\title{
Environmental Software Systems in National Park Monitoring and Management
}

\author{
Peter A. Fischer-Stabel ${ }^{1}$ \\ ${ }^{1}$ University of Applied Sciences Trier, 55761 Birkenfeld, Germany \\ p.fischer-stabel@umwelt - campus .de
}

\begin{abstract}
National Park (NP) Monitoring and Management is dealing with dozens of different data where the provenience of the data is as manifold as the fields covered in the monitoring process. International, national, and federal responsibility is found as well as NGO databases, crowd sourcing applications or dedicated field surveys in R\&D - activities of single research groups. Environmental software systems are intelligent pencils to manage, analyse and visualize the environmental- but also the administrative data coming from the different sources mentioned. The paper emphazises different fields of activity in NP monitoring and management and is presenting software systems in use in the NP Hunsrück-Hochwald (Germany).

In general, the software systems used are mostly highly adopted to the individual needs of a NP. This depends on specific landscape, features, or the research focus in the park, to name but a few. The software solutions are realized as a customization of standard software products, or, as individual software packages, designed and developed according to the special requirements of the fields of activity in a dedicated park.

Regarding the future developments, there will be no significant changes: the heterogeneity of the data and software used will be similar as it was in the past or it is recently. Because of the long-lasting perspective in NP research and management, one important action the NP administration should focus on: a proper documentation of methods, datasets, publications and information systems targeting the NP, to make monitoring and management activities transparent, accessible and ready for future re-use.
\end{abstract}

Keywords: National Park Monitoring - Environmental Software System · National Park Management.

\section{Introduction}

The world network of nature reserves has remarkable high natural values (high ecological integrity, high biodiversity, limited human use, rather unstressed systems, resource management is not extraction-oriented, etc.) and often high cultural values in addition. Within this network, because of their large coverage, especially the National

adfa, p. 1, 2011.

(C) Springer-Verlag Berlin Heidelberg 2011 
Parks (NP), but also the UNESCO MaB Biosphere reserves serve as sites for traditional environmental monitoring and, in addition, as laboratories for research and demonstration of ways in progressing towards sustainability of human-environment interactions (including wise-use and economic development). Terabytes of data are collected in the different application domains in the long term monitoring programs of a national park, but also in single one shot data acquisitions, analysing and discussing highly specialized research topics.

This paper gives an overview about the very high diversity of data collected in national park monitoring and management and of the variety of software systems required to deal with all these data. The concrete setting is the youngest national park in Germany - the NP Hunsrück-Hochwald, inaugurated in 2015.

\subsection{National Park Hunsrück-Hochwald}

Behind all national parks worldwide, there is a common idea: the conservation of 'wild nature' for posterity [1]. The International Union for Conservation of Nature (IUCN) discusses the parameters defining a national park. In 1969, the IUCN declared a national park to be a relatively large area (> $1000 \mathrm{ha}$ ) with the following defining characteristics [2]:

- One or several ecosystems not materially altered by human exploitation and occupation, where plant and animal species, geomorphological sites and habitats are of special scientific, educational, and recreational interest or which contain a natural landscape of great beauty;

- Highest competent authority of the country has taken steps to prevent or eliminate exploitation or occupation as soon as possible in the whole area and to effectively enforce the respect of ecological, geomorphological, or aesthetic features which have led to its establishment; and

- Visitors are allowed to enter, under special conditions, for inspirational, educative, cultural, and recreative purposes.

In addition, national parks can be used as laboratories for research and demonstrate ways to re-establish it's original, natural state. 


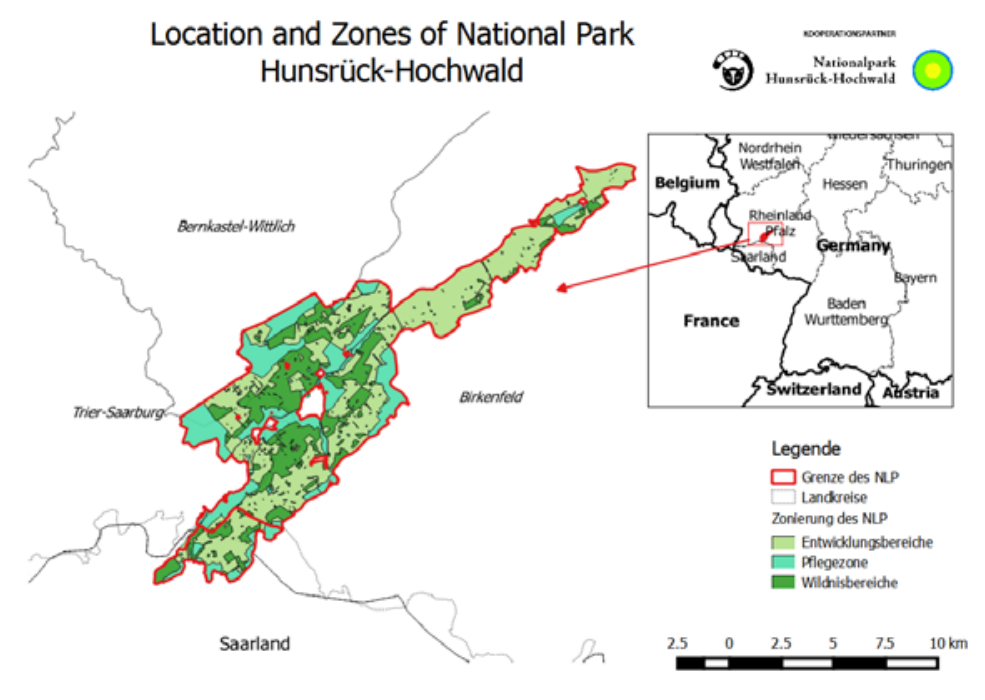

Fig. 1. Orientation Map of the National Park Hunsrück-Hochwald.

"To Leave Nature Nature" - this principle shall be realized in the most recent national park in Germany. After several years of planning, the NP Hunsrück-Hochwald was officially opened in May 2015. It is a part of the nature park Saar-Hunsrück and comprises approximately 10,000 hectares, or more explicitly, $5 \%$ of the total area. The National Park Hunsrück-Hochwald is located in the southwest Germany and connects the federal states of Rhineland-Palatinate and Saarland (see fig.1). A low mountain range with an almost never-ending forest area characterizes the Hunsrück and differentiates the area from the surrounding best wine-growing regions of Germany: the Moselle, the Rhine, the Nahe and the Saar. The Federal Agency for Nature Conservation already counts the Hunsrück as a "hot spot region for biodiversity" [3]. Therefore, visitors can especially experience one thing: forest and wilderness.

Research plays, in accordance with the concept of the national park, an important role in the park. Nature conservation, forest development and ecology as well as local added value and the acceptance of the national park by the regional population are examined.

\section{Data Sources}

In national park monitoring, software systems are intelligent pencils to manage, analyse and visualize the environmental data coming from lots of different sources. 
Therefore, before discussing environmental software systems, we will have a deeper view to the data collected in national park monitoring and management. Figure 2 gives an overview to relevant subject fields in the national park monitoring process.

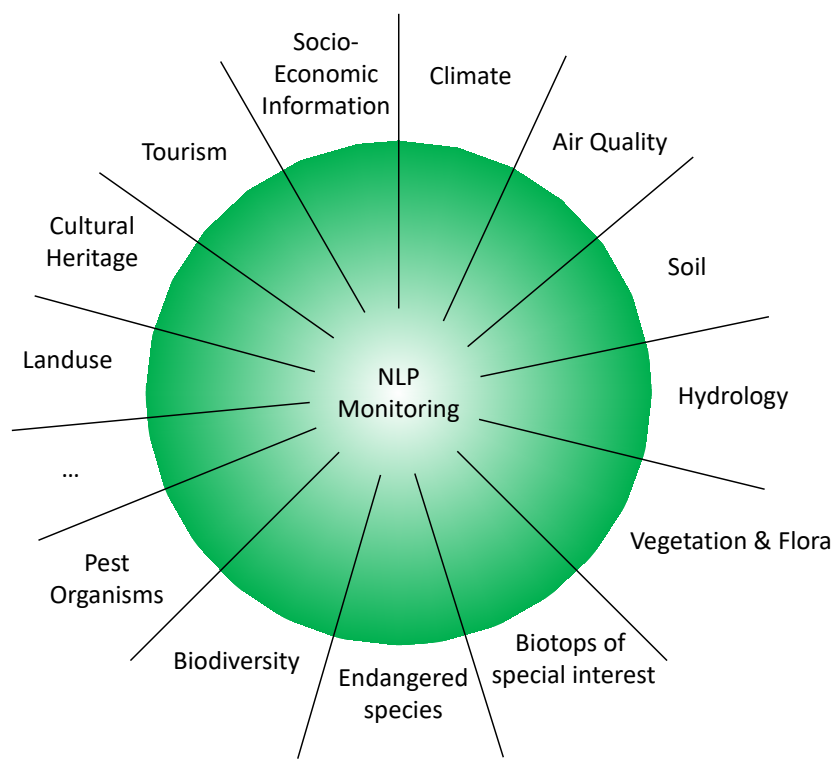

Fig. 2. Fields of Interest in National Park Monitoring - Overview.

Thereby, the provenience of the data is as manifold as the fields covered in the monitoring process. International (e.g. earth observation), national (e.g. hydrologic network) and federal (e.g. air quality measurements) responsibility is found as well as NGO databases, crowd sourcing applications or dedicated field surveys in R\&D activities of single research groups.

On the other hand, looking at the data sources, NP management is not as diverse as it is in the field of environmental monitoring. Only limited new data is collected (e.g. by Ranger activities in park supervision). In this application domain, tasks are focused on the documentation of ongoing activities including the characterization of the collected data sets, on presentation of derived information e.g. for educational activities and on mapping or Web applications. Figure 3 gives an idea about some activities in $\mathrm{NP}$ - management. 


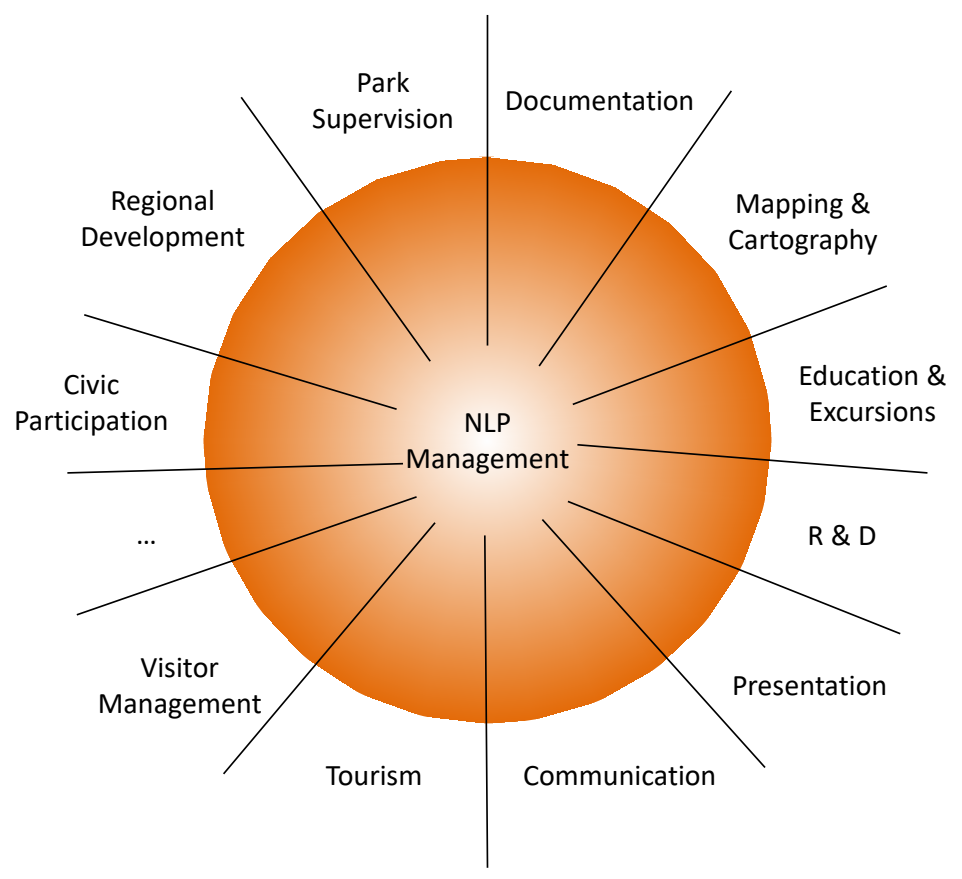

Fig. 3. Fields of Activity in NP - Management.

\subsection{Data Quality Aspects}

The data quality in data sets or in information systems becomes more and more important [4]. The quality of data is usually described by multiple dimensions, e.g. accuracy, completeness, consistency, relevance, accessibility and timeliness.

Quality defects during initial data acquisition lead to a huge additional effort to resolve. Practical experience showed that essential quality standards can easily be fulfilled by help of guidelines for data collection. Hence, corresponding guidelines should be worked out before the beginning of the collection, especially in long term monitoring programs. Additionally it must be defined how the data will be rechecked and actualised continuously.

Today, in national or federal monitoring programs, such as e.g. air quality monitoring, data quality aspects are addressed and appropriate actions are implemented [12]. On the other hand, with the installation of ad-hoc-networks or with some field surveys done by different research groups, aspects of data quality and representativeness often are not intensely discussed. In the worst case this can lead to data sets which are not usable in other context than the one focused on in the dedicated research. 


\section{Software Systems in NP Monitoring and Management}

Because of the high diversity of the data in NP monitoring and management, there is no generic software available, dealing with all the different data in one shell. Beside some typical standard tools as e.g. Geographic Information Systems, Database Management Systems or even Spreadsheet Software, highly specialized software is in use to support the requirements of a national park monitoring. Due to the high importance of the spatial information of the data in environmental monitoring, the ability to store and to deal with this kind of information is common to all software systems used in this context.

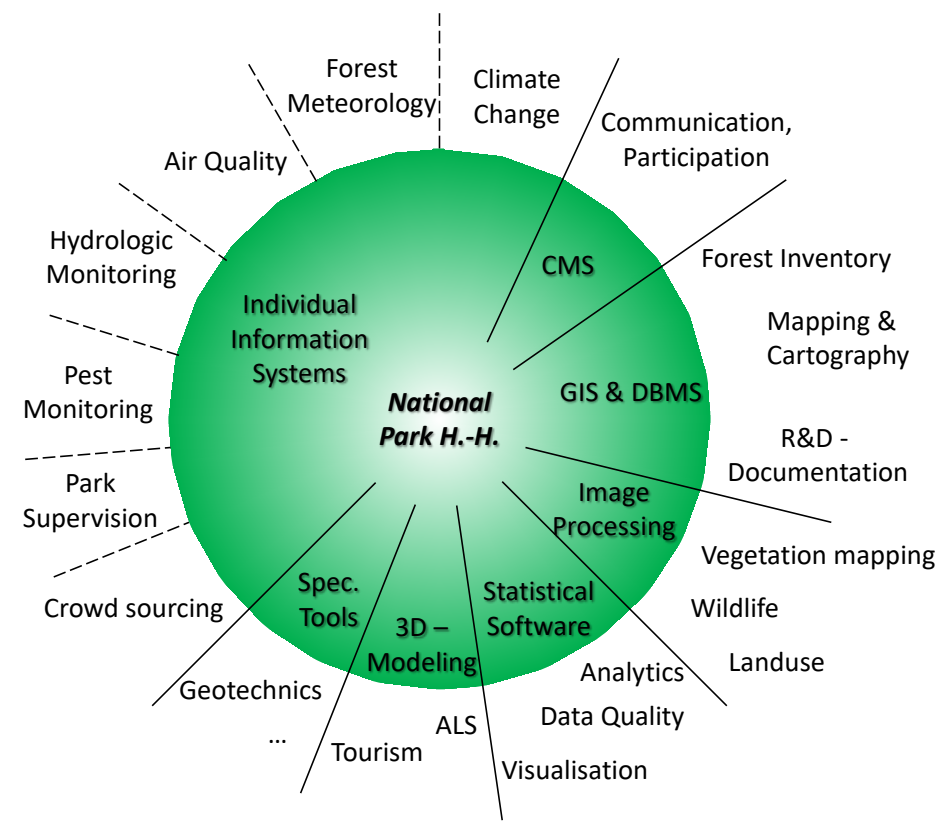

Fig. 4. Software in use in Monitoring and Management of the NP Hunsrück -Hochwald

As shown in figure 4, there are a lot of individual software systems in use in the NP Hunsrück-Hochwald. Below, you will find a short description of these software systems. Because of the individual needs of the different national parks, the list below is without claim of completeness.

\subsection{Standard Software}

There are some standard software systems used in environmental monitoring programs in general. Below, some of them, which are in use in the NP HunsrückHochwald, are listed:

- Geographic Information Systems (GIS): GIS are systems designed to capture, store, manipulate, analyze, manage, and present spatial or geographic data. Different technologies and methods are the foundation. Depending on the underlying 
functionality and the familiarity of the user with the system, GIS are in use for documentation, analyzing and mapping of mainly vector data as e.g. Biotopes, Permanent Observation Areas (e.g. matured forest cells) or the Forest Inventory. In addition, the use of standardized display- and download services (e.g. WMS, WFS, WCS) offered by third party data provider (e.g. land surveying agencies) via spatial data infrastructures (SDI) is a further important functionality.

- Image Processing Software: Processing of images using mathematical operations by using any form of signal processing for which the input is an image, a series of images, or a video, or a photograph. In NP-monitoring, main sources for image data are Earth Observation (Single spectral- / Multi spectral images in different spatial resolutions), Photo Traps (daylight or infrared photographs), Pass by imagery (daylight photographs), or even earth borne change detection photography systems (e.g. $360^{\circ}$ recording).

- Database Management System (DBMS): A DBMS is the backbone in NP data management. If appropriately designed, it is able to integrate most of the different data gathered. In addition, the software can interact with further tools in use, such as GIS, statistical packages or content management systems.

- Statistical Packages: As specialized software for analysis in statistics, these tools are widely used to analyze and visualize e.g. sensor data regarding trends, in change detection analysis (e.g. climate change) but also in data quality management. Further applications are e.g. the estimation of population density of wildlife [5] or, with Geostatistics, focusing on spatial or spatiotemporal datasets.

- Spreadsheet Software: Widely used in field data collection, such as mapping of species including endangered or pest organisms, or as data sheets in vegetation or soil mapping.

- Content Management Systems (CMS): Software that supports the creation and modification of digital content, mainly used in Web content management to publish national park activities for the public, but also as Intranet for the staff. It is often used to support multiple users working in a collaborative environment.

- 3D-Modeling Software: 3D modeling is the process of developing a mathematical representation of any three-dimensional surface of an object. With the event of Roomscale VR applications or interactive App guides, 3D - modeling starts it's career even in national parks. Especially cyber physical systems are now dealing with tourism promotion activities. In our case, some developments combining the recent earth's surface derived from laser scanning data with reconstructed ancient roman and celtic sites are under way and promoted because of their innovative aspects.

- Geotechnical Software: Because of the specific geomorphologic situation and the presence of endangered biotopes as peat bogs, 3D soil- and drilling profiles but al- 
so data coming from Palynology analyses have to be documented and analyzed in our reference national park. Specialized, commercial of the shelf software is supporting the scientists in this field of research.

\subsection{Individual Software}

Beside the standard software packages, there are some individual software and dedicated information systems in the monitoring and management of the NP HunsrückHochwald in use. Configured and developed for the special needs in individual parks, each park will have its own individual software, depending on the natural resources (e.g. forest, grassland, maritime) and/or on the focus of the development of the park.

- Documentation System of R\&D-Activities: In order to ensure central and efficient access to the literature and data of the NP for all scientists from the respective institutions and for a long-lasting period, in the NP Hunsrück-Hochwald a "research server" was established. The system serves future researchers as a scientific information portal. The goal is to avoid expensive, redundant data acquisition as well as time-consuming information retrieval for the individual teams. Furthermore, research becomes more transparent and allows better use of possible synergistic effects [6]. The system of the NP Hunsrück-Hochwald is accessible under: http://fs.nlphh.de/

- Pest Monitoring System: Because of its special forest structure, the national park Hunsrück-Hochwald must be monitored regarding bark beetles calamities (mainly Ips typographus), to avoid significant damages in forests neighboring the park. This is done with a specific monitoring system collecting activity data of the beetles in traps, modeling the evolution of the population and resulting in an estimation of the damage risk for the forest. If there is a high damage risk for the forest, the NP administration has to take action to protect the forest outside the park. Further information can be found in [7]. The system is available under: http://ifffriskanalyses.boku.ac.at/typo3/index.php?id=74

- Dedicated Apps: With the intensive use of smartphones and field clients, there are dozens of Apps in use in NP-monitoring and management [8]. Combining the ability to collect position information and link it with attribute data, Apps are supporting the rangers in park supervision, the collection of species data or are in use in crowd sourcing applications, e.g. monitoring the spread of invasive organisms. An example in the field of species data collection for the NP Hunsrück-Hochwald can be found under http://www.buergerschaffenwissen.de/projekt/artenfinderrheinland-pfalz.

- Laser Scanning Software: Airborne Laser Scanning (ALS) data acquisitions are providing the scientific community with very high resolution $3 \mathrm{D}$ - data regarding the earth's surface. Starting with the raw point cloud data, specialized software tools are in use to derive high resolution elevation- but also surface models serving 
as input for many applications (e.g. vegetation analysis, erosion processes, micromorphological studies). In addition, the latter provide suitable information for 3D modeling applications.

- Camera Trapping Software: Camera trapping is increasingly becoming an important tool in ecological research. Capture-recapture surveys or the simple documentation of wildlife are nowadays common projects in national parks, collecting thousands of pictures. However, the organization of large collections of multimedia files and especially the efficient search for subsets of data is a challenging task. Camera trapping software makes classifying camera trap photos quick and easy, keeps track of camera trap, camera and species data and supports the management and retrieval of the photographs $[9,10]$.

- Forest Meteorology and Climate Change Information System: This information system is a cross-section task with the emphasis on data management, information, consulting, advanced training and contacts at the different levels of expertise. The central product of the climate change information system is a publicly accessible web portal, which is intended to appeal to a broad public. The user is offered detailed information on climate change and possible consequences for the Rhineland-Palatinate but also for the National Park. Further Information to the information system can be found under http://www.klimawandel-rlp.de/ or www.am.rlp.de/

- Immission Monitoring Network and Information System: Since 1978, the agency for environment Rhineland-Palatinate has been operating the Central Immission Monitoring Network (ZIMEN) for Rhineland-Palatinate on behalf of the Ministry of Environment, Agriculture, Food, Viticulture and Forestry. This consists of 27 air measuring stations, which are telemetrically supervised by a measuring network in Mainz. It has the task to determine the long-term development of the air pollutants in cities and forest areas of the country by continuous measurements, in order to achieve a high protection level for human health and the environment [11,12]. (www.luft-rlp.de/ )

- Hydrologic Monitoring Network and Information System: On the one hand, the system is providing a quantitative measurement service on surface waters, precipitation and groundwater. Quantitative management of surface waters, management of groundwater and the protection of springs are tasks supported by the information system. Especially within, and in the surroundings of the NP Hunsrück-Hochwald, with its mineral springs and spa waters, there is a special focus on hydrologic monitoring. (www.quellenatlas.rlp.de/ , geoportal-wasser.rlp.de/ )

- Tools for Communication, Civic Participation and local Governance: Democracy relies on citizens participating in decision making, even or especially in national park regions with restricted use in landscape. Web 2.0 technology is enabling citizens to make their voices heard in new and innovative ways, important for 
civic participation and the decision making process in regional development. Some product examples can be found under [13, 14].

\section{$4 \quad$ Summary and Outlook}

Types of software systems used in NP monitoring are as manifold as the fields of scientific- and management activities are occuring in a park.

In general, software systems in NP monitoring and management are mostly highly adopted to the individual needs of a NP. This depends on specific landscape, features, or the research focus in the park, to name but a few. The software solutions are realized as a customization of standard software products, or, as individual software packages, designed and developed according to the special requirements of the fields of activity in a dedicated park. The case described in the paper was the NP HunsrückHochwald (Germany).

In addition, the heterogeneity in software and information systems used in parks is strongly linked to the evolution process in environmental monitoring: Often, monitoring systems as e.g. air quality, hydrologic monitoring or forest inventory are implemented decades before the government decided, to install a national park in the region. Keeping this in mind, a mixture between historic and recently designed sensor networks and software systems is available. Especially with view to the long-term perspective, it is still difficult today, to combine and use all the information available in an integrated environmental monitoring in the park.

Regarding the future developments, it is the opinion of the author that there will be no significant changes: the heterogeneity of the data and software used will be similar as it was in the past or it is recently.

But, especially because of the long-lasting perspective in NP research and management, one important action the NP administration should focus on: a proper documentation of methods, datasets, publications and information systems targeting the $\mathrm{NP}$, to make monitoring and management activities transparent, accessible and ready for future re-use.

\section{References}

1. Europarc Federation (eds.) 2009. Living Parks, 100 Years of National Parks in Europe, Oekom Verlag, Munchen

2. Gulez, Sümer 1992. A method of evaluating areas for national park status.- Environmental Management 1992, Volume 16, Issue 6, pp 811-818

3. Ackermann, W., Sachteleben, J., 2012. Identifizierung der Hotspots der Biologischen Vielfalt in Deutschland.- BfN-Skripte 315, Bundesamt für Naturschutz (BfN), Bonn

4. Redman, T.C. (2001): Data Quality - The Field Guide, Digital Press 
5. Ebert, C. et al. (2012): Estimating wild boar Sus scrofa population size using faecal DNA and capture-recapture modelling.- Wildlife Biology, 18(2):142-152.

6. Fischer-Stabel, P., M. Mattern (2016). Scientific Research Documentation - An Information Server for the National Park Hunsrück-Hochwald.- International Environmental Modelling and Software Society (iEMSs), Proceedings of the 8th Int. Congress on Environmental Modelling and Software, Touluse, France

7. Delb, H., S. Pontuali (eds.) (2011): Biotic Risks and Climate Change in Forests. Proceedings of the IUFRO Working Party 7.03.10 Methodology of Forest Insect and Disease Survey in Central Europe, 10th Workshop September 20th- 23rd, 2010, Freiburg, Germany. Berichte Freiburger Forstliche Forschung Heft 89, FVA, 198 p.

8. Newman, Greg et al. (2012): The future of citizen science: emerging technologies and shifting paradigms.- Front Ecol Environ 2012; 10(6): 298-304, doi:10.1890/110294

9. Bubnicki, J. W., Churski, M. and Kuijper, D. P. J. (2016), trapper: an open source webbased application to manage camera trapping projects. Methods Ecol Evol, 7: 1209-1216. doi:10.1111/2041-210X.12571

10. Smeedley, Richard (2015): Snoopy. Portable software for capture-recapture surveys.https://prezi.com/xqoogmni0ymu/snoopy/?utm_campaign=share\&utm_medium=copy; last access: 28.02.2017

11. Georgii H.-W. (Eds) (1982): Atmospheric Pollutants in Forest Areas: Their Deposition and Interception.- Kluwer Academic Publishers

12. Federal Environmental Agency (2004): Determination and Evaluation of Ambient Air Quality - Manual of Ambient Air Monitoring in Germany; Research Report 20042261 UBA-FB

13. Platforms for civic engagement; http://www.shareable.net/blog/14-online-platforms-thatboost-civic-engagement; last access: 28.02.2017

14. Software in civic participation; http://www.xpolitics.de/2013/01/24/update-softwareanbieter-digitaler-burgerbeteiligung/; last access: 28.02.2017 